\title{
The process and patterns of combining the use of Traditional Chinese Medicine and Western medi- cine in Taiwanese people with cancer
}

\author{
Shou Yu Wang ${ }^{1}$, Carol Windsor ${ }^{2}$, Patsy Yates $^{2}$ \\ 1. Department of Nursing, HungKuang University, Taiwan. 2. School of Nursing, Queensland University of Technology, \\ Brisbane, Queensland, Australia.
}

Correspondence: Shou Yu Wang. Address: No. 34, Chung-Chie Rd., Shalu, Taichung City, Taiwan 43302, R.O.C. Department of Nursing HungKuang University. Telephone: 886-426-318-652 ext: 3031. Email: cindyla_tw@yahoo.com

Received: February 11, 2012

Accepted: J une 20, 2012

Published: November 1, 2012

DOI : $10.5430 /$ jnep.v2n4p134

URL:http://dx.doi.org/10.5430/jnep.v2n4p134

\section{Abstract}

Objective: The nature of contemporary cancer therapy means that patients are faced with difficult treatment decisions about surgery, chemotherapy and radiotherapy. For some, this process may also involve consideration of therapies that sit outside the biomedical approach to cancer treatment, in our research, traditional Chinese medicine (TCM). Thus, it is important to explore how cancer patients in Taiwan incorporate TCM into their cancer treatment journey. This paper aims to explore of the patterns of combining the use of TCM and Western medicine into cancer treatment journey in Taiwanese people with cancer.

Methods: The sampling was purposive and the data collected through in-depth interviews. Data collection occurred over an eleven month. The research was grounded in the premises of symbolic interactionism and adopted the methods of grounded theory. Twenty four participants who were patients receiving cancer treatment were recruited from two health care settings in Taiwan.

Results: The study findings suggest that perceptions of health and illness are mediated through ongoing interactions with different forms of therapy. The participants in this study had a clear focus on "process and patterns of using TCM and Western medicine”. Further, 'different importance in Western medicine and TCM', 'taken for granted to use TCM', 'each has specialized skills in Western medicine and TCM' and 'different symptoms use different approaches (Western medicine or TCM)' may explicit how the participants in this study see CAM and Western medicine.

Conclusions/Implications for practice: The descriptive frame of the study suggests that TCM and Western medicine occupy quite distinct domains in terms of decision making over their use. People used TCM based on interpretations of the present and against a background of an enduring cultural legacy grounded in Chinese philosophical beliefs about health and healthcare. The increasingly popular term of 'integrative medicine' obscures the complex contexts of the patterns of use of both therapeutic modalities. It is this latter point that is worthy of further exploration.

\section{Key words}

Cancer patients, Traditional Chinese Medicine, Grounded theory 


\section{I ntroduction}

The nature of contemporary cancer therapy means that sufferers are often faced with difficult decisions as they encounter a complex range of treatment options such as surgery, chemotherapy or radiotherapy. For some with cancer, this may involve consideration of therapies that sit outside the biomedical approach to cancer treatment. In Taiwan and China, many patients also incorporate approaches and medicines from Traditional Chinese Medicine (TCM) and such therapies have growing demand ${ }^{[1-3]}$. Within the biomedical framework, integrative therapies are typically defined as therapies that supplement conventional (mainstream) treatments to promote healing, increase comfort and enhance health. In cancer treatment, integrative therapies such as TCM are generally conceived of as regimens that are not substitutes for mainstream treatments ${ }^{[4-5]}$.

In contrast to the West, for those in the East where there has been a rich and sustained history of the use of traditional therapeutic forms. TCM has been used to treat and prevent diseases for over 3000 years, has endured as a mainstream therapy intervention in mainland China and Taiwan ${ }^{[6]}$.

Nonetheless, over the past century or more, there have been significant changes in the structure and delivery of health care in East Asian countries. This has occurred as the influence of modern scientific medicine has pervaded these societies. In Taiwan and prior to the Japanese occupation of 1895, the mainstream health care system was dominated by TCM. During the five decades of the Japanese occupation, the practice of Chinese medicine was constrained through regulation and the focus shifted to the development of modern Western medicine ${ }^{[7]}$. Western medical schools were established, more and more Taiwanese people were exposed to Western medicine and the use of traditional therapeutic modalities was severely undermined.

However, a further phase of significant change occurred following the transfer of political power over Taiwan to the Chinese Nationalist government at the end of World War II. This was accompanied by high level state intervention and a commitment to restore the status of TCM ${ }^{[8]}$. In Taiwan, the first medical college dedicated to the development of TCM (The China Medical College, now known as the China Medical University) was established in the early 1950s and the practice of TCM was officially recognised in 1956 with the passing of the Chinese Education Act. From this point on, TCM and Western medicine have been acknowledged as legitimate and co-existing regimes of health care in Taiwan and mainland China ${ }^{[7]}$. This co-existence was more formally recognised in the institution of the 1995 Taiwanese National Health Insurance coverage of which TCM is a part.

It is within the context of the relatively complex history of the suppression and resurgence of non-Western medicine in Taiwan that the research reported on in this paper sought to explore the ways in which Taiwanese people with cancer incorporated different health care regimes during their cancer treatment journeys. The paper addresses, specifically, the patterns of use of both the TCM and Western therapeutic modalities in those with cancer.

The rationale for the study was grounded in the differences that exist in the meanings attributed to diseases and health in Western and Eastern cultures. Western medicine typically focuses on the treatment of specific diseases which, in turn, are conceptualised as malfunctions of particular parts of the body. The objective of Western medical intervention is thus to improve or reverse such malfunctions. This is akin to perceiving the human body as a machine and medicine as an instrument, the use of which eliminates symptoms and enhances the body's performance ${ }^{[9]}$.

The concern of Eastern medicine, by contrast, is with the body as a whole and the body in context in addition to discrete body parts and functions. Diseases are perceived and treated based on their morphology, associated patterns of signs and symptoms and inherent responsivity in the short and long term ${ }^{[10,11]}$.

TCM is seen by many Taiwanese as a gentle therapy and one valued for sustaining and restoring health ${ }^{[13,15-17]}$. In contrast, Western medicine is seen as intense and controlling and producing many side effects. As some have argued, these 
distinctions translate into decisions on treatment use dependent upon the disease and/or symptoms that have manifested ${ }^{[16,18,19]}$. Therefore, it is important to understand the process of using both TCM and Western medicine during the disease and treatment trajectories.

\section{Aims}

In applying the theoretical premises of symbolic interaction, the study was to explore the process and patterns of combining the use TCM and Western medicine in Taiwanese people with cancer.

\section{Methods}

Herbert Blumer ${ }^{[20]}$ argued that society as a whole may be viewed as symbolic interaction. Consistent with this premise, the study of human life and social action considers the realm of life under study as a dynamic process whereby participants give meaning to the actions of others and, as a consequence, define and interpret their own actions. In other words, people construct their actions through an interpretation of the contexts within which they live. Construction occurs through the interaction of social structural pasts and symbolic interpretative processes. Thus, social interaction and context and how these shape experiences are fundamental to our understanding of TCM use ${ }^{[21]}$.

Two key points emerge from this understanding. First, human actions exist as a relationship between subject and object and not simply as a response by subject to object ${ }^{[22]}$. Second and in contrast to Blumer's ${ }^{[20]}$ reference to structural concepts as 'obdurate facts', context and structure are integral to the conditioning of meaning and human actions take different forms within different contexts. As Maine ${ }^{[21]}$ argues, meaning construction occurs through the interaction of social structural pasts and symbolic interpretative processes. Thus, social interaction and context and how these shape experiences are fundamental to our understanding of TCM use by Taiwanese patients.

The research adopted the methods of grounded theory as developed by Strauss and Corbin ${ }^{\text {[23] }}$. Grounded theory method, as a process, seeks to explicate a connection from qualitative data to theoretical propositions. It is, therefore, the conceptual relationship between the methods, not the order in which they are employed, that enables a systematic and cumulative construction of an analysis. In this sense, the process is almost in the data and naturally emerges from the data analysis if the researcher follows the steps of grounded theory analysis ${ }^{[23,24]}$.

\subsection{Sample}

Before the study was conducted, ethic approvals were obtained from two health care settings. Twenty four participants who were patients receiving cancer treatment were recruited from two health care settings; a medical centre hospital (the largest) and a regional hospital (the second largest) in Taiwan. The criteria for participant selection were as follows: firstly, participants had been diagnosed with cancer; secondly, participants had used at least one type of TCM therapy during their cancer treatment journey for any length of time. Finally, the participant's health status was such that she/he could participate fully and without adverse effects in the interview process.

The sample constituted thirteen males and eleven females diagnosed with a range of cancers at various stages of disease. Ages ranged from 16 to 69 years with a mean age of 45.7 years. Of the sample, 18 were married, four participants were single and two widowed. In regard to religious beliefs, a majority (21/24) embraced Eastern based religions such as, Buddhism, Taoism and folk beliefs. One participant expressed ambivalence about religion and two others held no religious beliefs. Eleven of the twenty four participants had finished either primary or junior high school, ten had an education level of senior high school and the others held a bachelor degree or higher. In this study, we identify the twenty-four participants by pseudonyms, family names, such as Mr. Sun, in order to protect the participants' anonymity and confidentiality.

\subsection{Data Collection}

Sampling was purposive and data was collected over a period of eleven months and the process was conducted in two stages. Fourteen interviews were undertaken during the first stage. The other ten interviews were conducted in the second 
stage by using theoretical sampling to confirm emerging categories. Data analysis of Taiwanese patients' interview transcripts then proceeded and categories within this data were identified for further exploration. The subsequent ten interviews were conducted with the objective of addressing conceptual gaps and producing further categories.

Participants received a written information sheet and consent form in Chinese. Full information about the study purpose and the areas to be discussed was provided prior to the interview in the participant's most familiar language. Furthermore, participants were informed that they were free to withdraw at any time from the research, without comment or penalty and without endangering their relationship with healthcare providers or the hospital. Each participant signed a privacy consent form before taking part in an interview. Finally, fictional names have been used in data storage, analysis and presentation to ensure anonymity of participants.

\subsection{Data analysis}

The data were analysed using the phases of open, axial and selective coding to the data to produce, in turn, concrete concepts and broad categories ${ }^{[23,25]}$. Further, the analysis process may go back and forward between different levels of coding. Moreover, the strategies of asking questions and comparative analysis are used in this study ${ }^{[12,23]}$. Line-by-line in vivo coding was the defining feature of open coding. Here the codes were drawn directly from the data and not from preconceived concepts or ideas ${ }^{[26,27]}$. When it came to axial coding, the numerous codes from open coding were further interpreted to produce broad (inclusive) categories.

The adequacy of the research process needs to be judged, because it may affect the substantive category which is being tested or elaborated ${ }^{[23]}$. In this study, the research process can claim rigour as a result of the following steps. First, there was a clear understanding grounded theory methodology and methods prior to the commencement of the study. Second, the substantive category in this study directly informs the research purpose which was to determine how and why Taiwanese cancer patients incorporated the use of both TCM and Western medicine in their treatment regimes. Furthermore, the substantive category is relevant to the participant group in this study. Moreover, rigour also reached by data analysis which include detail memo writing, transcripts verbatim and keeping detail data analysis records during the research process ${ }^{[28]}$.

\section{Results}

We found the participants in this study had a clear focus on "process and patterns of using TCM and Western medicine" during their cancer journeys. It emerges as the core category in this study. Further, the following categories, 'different importance in Western medicine and TCM', 'taken for granted to use TCM', 'each has specialized skills in Western medicine and TCM' and 'different symptoms use different approaches (Western medicine or TCM)' may explicit how the participants in this study see and use TCM and Western medicine during their cancer treatment journeys (see Figure 1).

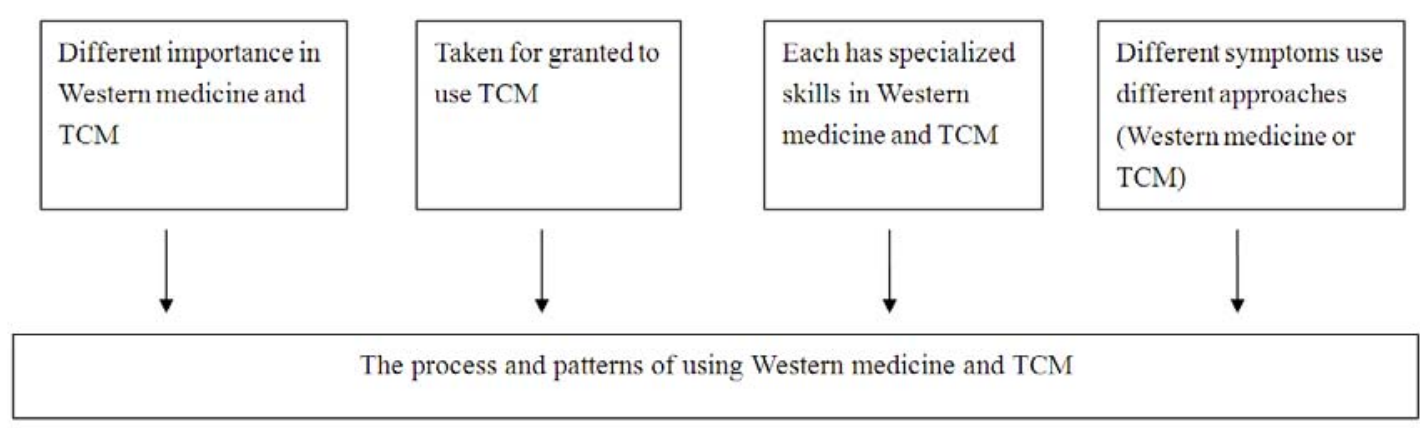

Figure 1.The process and patterns of using Western medicine and TCM 


\subsection{The process and patterns of use of Western medicine and TCM}

\subsubsection{Different importance in Western medicine and TCM}

The patterns when combining the use of TCM and Western medicine in Taiwanese people with cancer are various. Some participants see as a process of incorporation between TCM and Western medicine. Some see one is more important than the other.

Ms. Chu described a process of incorporating the two modalities:

I still mainly use Western medicine and use Chinese medicine as complementary. (I use) them (healthy products) as dessert...I take Western medicine before meals and after meals, I take Chinese medicine, one hour apart between the two...

Yet, a focus on the concurrent use of TCM and Western medicine obscures quite different views of the two therapeutic approaches. There are those who decisively believe in Western medicine: I mainly use Western medicine. After all, this medicine is more based. Those non traditional (treatments) are mostly word of mouth. (Ms. Han). And: Cancer cells need to rely on Western medicine...this disease needs to rely on Western medicine. Others are complementary. (Ms. Zhu)

For Ms. Qian, Western medicine was the only cancer therapy to be considered:

...for example, now you are more serious, (you) should use Western medicine. Western medicine is the best treatment. It suppresses it (cancer). When (you) get well and stable then (you think about) maintenance. This is right. This is more correct...when you get a serious disease, (it is) impossible to use Chinese medicine.

Others are of the view that both Western and TCM hold an important place in Taiwanese health care although performing quite divergent functions in cancer treatment. In Mr Shi’s words:

Chinese medicine, if (they are) symptoms, (they) can be treated. If it is cancer, Chinese medicine may not be able to deal with it...so Chinese medicine has its benefits; it can deal with small symptoms...such as a cold, bones, soreness, Chinese medicine can deal with those. As far as cancer cells, it just can't.

Such a view may explain the perception of some that TCM treats symptoms only, that it is an interim measure and that it will not affect a permanent cure. As Mr. Chen stated:

...it is impossible to treat cancer by using Chinese medicine... (In Chinese medicine) you take something poison and see if it leads to (cancer cell's) death. Yes, but it is a stopgap measure that is not effective for achieving a permanent cure...

Mr. Yang also stated: I feel that Chinese Medicine does not affect a permanent cure; it only takes stopgap measures.... Thus, for some and where TCM is used by those with cancer, it is generally to alleviate symptoms.

\subsubsection{Taken for granted to use TCM}

Notably, the researchers found that during the process when combining the use of TCM and Western medicine in this study, some participants take for granted when using TCM. The study revealed a taken for granted sense of the use of TCM. As Mr. Zhao stated:

After I took this (healthy product), (my) body became very healthy and was in very good spirits. (It)(healthy product) treated your disease if you had one; if you did not have disease, it could help you to take care of (your) 
body. My friend... who is a teacher...I also gave (it to) him. He said all was good after taking (it) (healthy product).

Mr. Li explained in some detail the practice of Guo Lin Xin Chi Gong:

I feel this (Guo Lin Xin Chi Gong) is better. Why? The reasons are written inside here (the book of Guo Lin Xin Chi Gong). The reason is because the cancer cells do not like oxygen, (you) breathe in (with the action of breathing in) and bring in a lot of oxygen in red blood cells. At this time, it (the oxygen) can control cancer cells, even kill cancer cells. So, it (the cancer cells) shrinks. The cancer cells shrink and shrink. Let them (the cancer cells) wither away...

\subsubsection{Each has specialized skills in Western medicine and TCM}

For other participants, there was no clear distinction made between Western medicine and TCM in terms of potential to cure illness. Each has specialized skills. As Ms. Zhu commented:

I feel everything has its best kick and has its advantages and disadvantages...somebody takes Chinese medicine or herb medicine then gets well...somebody controls quite well, somebody is cured by Western medicine.

Another participant (Ms Qin) shared her experiences:

(I) caught a cold, (I) could not get well after catching a cold for a long time. (I) then tried Chinese medicine, and then Western medicine. I went to see the ear, nose and throat doctor. Then, I came back to see Chinese medicine doctor... then again the ear, nose and throat doctor...

However, while some participants saw Western medicine as fundamental to their cancer treatment and others perceived TCM as just as valid a therapy, there was a strong and shared sense that Western medicine weakened the body and that TCM gave support to the body. For example, Mr. Sun stated:

(I) mainly took healthy products, because they (healthy products) had fewer side effects and less damage to the body. If (I) took Western medicine, (it) might cause liver, stomach or kidney (pause) so I avoided it if I could. I took less medicine. I relied on exercise.

Ms. Zu also commented:

I thought I will be cured when I try this (FaLun Gong), because there are always side effects in Western medicine. I felt scared. I was afraid of what would happen after taking (Western medicine)...One time, after I took and injected medicine (for a period of time), I developed earache. Nothing was found after examination. (It) can't be treated. (It) was very painful. (My) ears were suddenly cured after I practiced FaLun Gong.

In addition, Mr. Jiang mentioned his experiences:

Personally I mostly take Chinese medicine...medicine does not damage the stomach so much. Although it is not so quick to be effective, it is better for the body.

Other participants started to use TCM immediately following diagnosis and not in conjunction with Western medicine.

Doctor X told me that I was diagnosed as lymphoma. After three or four days, I started to take Niu Zhang Gu (one kind of mushroom). I knew it from more than twenty years ago...I do not want to have conflict with Western medicine...I then avoided it as much as I could. I stopped one week because of chemotherapy. Then, I took it 
everyday...(but) I stopped them (Niu Zhang Gu and other herbs) when I was admitted into the hospital...stopped all of them. (Mr. Wei)

The significance of TCM use as a discrete, rather than complementary, therapy was reflected in the timing by which such therapies were used. In some instances, participants modified their treatment programs depending on their perceived responses to treatment.

If sometimes you take Western medicine, but it is not effective, (you) try Chinese medicine. (You) take Chinese medicine for a while and then (you) take Western medicine for a while. Like this, you change back and forwards (Ms. Qin).

Mr. Chen stated:

(I) started when the disease was found...HeiTeng (one kind of herbs)...(I) sent (it) to somebody to grind into powder and take it as powder, or boil it with water and drink as tea...(I) stopped (it) when (I was) doing chemotherapy, this is anti-poison. That (chemotherapy) is poison, I was afraid they would clash with each other. I did not dare to take them at the same time...I feel this is effective...

In contrast, Mrs. Zhang ceased herbal medicine when her health deteriorated and sought further advice and treatment from Western medical practitioners.

(I) couldn't walk...suddenly (I) couldn't walk with support. (We) then went to hospital. I stopped taking (herbal medicine) and then my son worried, too. (We) then went quickly to the hospital (Mrs Zhang).

\subsubsection{Different symptoms use different approaches (Western medicine or TCM)}

Where circumstances change, an individual will structure and restructure priorities and values in relation to healthcare. An individual's conceptualisation of health and priorities is an ongoing and interactive process which explains why a range of decisions are made about the use of Western medicine and TCM. Some participants used different therapies concurrently and others vacillated between one or the other treatment mode depending on experiences and contexts. This is reflected in Mr. You's experience:

(I) hurt my back. (I) went to $X$ hospital. (I) had X ray...nothing was found and he (the doctor) said (you) may be too tired, hurting the nerve. After one month, (I) was still sore. (I) changed to Chinese medicine massage for four times. (I) got very sore in the middle of the night after the fourth time. Then (I) changed to Western medicine the second day. (I) had a needle and injected pain killers. (I) saw Western medicine doctor, took the medicine and had a needle. (I) still felt pain the second day...(and) a dry cough, dry cough. Sometimes (I) took Chinese medicine, sometimes (I) took Western medicine. Then, it got better, not coughing...

And in Ms. Qin’s account:

The doctor asked me to do chemotherapy. (I) heard somebody say doing chemotherapy is terrible...(I) did not dare to do it. It was delayed for one month and I went to see the Chinese medicine doctor. Somebody introduced (him) to me. It is not the one I see now. Then, I took (Chinese) medicine for one month. I had a very serious cough at that time. It was a very serious cough. I almost couldn't breath. At that time, I decided I still needed to do chemotherapy...

As the data suggests, perceptions of health and illness are mediated through ongoing interactions with different forms of therapy. Thus, why and how people with cancer determine their use of treatment modalities may alter over time and the 
meanings attributed to therapies are formulated and reformulated throughout the cancer journey. This intricate process of decision making is, importantly, also grounded in a long tradition of philosophical beliefs.

\section{Discussion}

The philosophies of Confucianism and Taoism which have underpinned Chinese traditions thousands of years are central to social, moral, political and cultural affairs. TCM has its origins in the dual power of Yin and Yang theory ${ }^{[29,30]}$ which, in turn, is symbolic of both Confucianism and Taoism. TCM is a clinically syncretic medicine that is able to incorporate theories and modalities alongside one another, even when those theories seem to conflict. A rule of thumb in TCM is to use what works ${ }^{[10,11]}$.

Therefore traditional thinking and syncretic flexibility among Taiwanese people impacts on how they interact with TCM and Western medicine. In addition, these philosophical concepts shape people's attitudes about cancer and actions in response to cancer, for example, they may see TCM and Western medicine as different importance in their cancer treatment journey. Moreover, because of traditional and philosophical views, people with cancer may take for granted when they use TCM. Yet, this is understood as an interactionist, not reactive, process. Consistent with Chinese philosophy, just as the existence of one phenomenon is never devoid of the whole, so the thoughts and actions of people alter according to changing experiences. We understand actions on the use of TCM and Western medicine thus as purposive, negotiated and constructed in particular contexts.

A most obvious pattern found in this study was the simultaneous use of Western medicine and TCM. The concurrent use of the two regimes has been found to be a common practice among Taiwanese (between $60-82 \%$ of people) ${ }^{[14,32-34]}$. On the other hand, studies of Taiwanese patients suggest that there are differences in views regarding the use of TCM. In the Chi et al. study ${ }^{[35]}$, participants were divided on whether the more effective regime for treating cancer and other potentially terminal diseases was Chinese medicine (24.2\%), or Western medicine (27.5\%).

Also, the Chi et al. study ${ }^{[35]}$, noted above, found that a majority of participants considered Chinese medicine a better option in treating conditions such as a fracture or sprains. Hu's study ${ }^{[19]}$ similarly found that people in Taiwan turn to TCM treatments for fractures and for nourishing the body after illness. Western medicine, then, is considered the treatment of choice for acute or serious health situations by some ${ }^{[36]}$. The findings of this study also found that cancer patients may use different approaches to different symptoms.

In addition, a much earlier study by Martin ${ }^{[37]}$ of medical systems in a Taiwanese village found the dominant view to be that Chinese medicine 'cures the cause' and Western medicine 'cures the symptoms'. It might be assumed that the recent development of more sophisticated Western medical therapies and what is depicted as an increasing integration of health care approaches in Taiwan ${ }^{[38,39]}$. Yet, some decades later, Wang's study ${ }^{[16]}$ of people residing in central Taiwan also found that two thirds of participants believed that Traditional Chinese medicine had a greater capacity to eradicate disease than Western medicine. It may reflect concern about aspects of Western medicine and specifically the side effects of invasive treatments. Indeed, a number of studies ${ }^{[40-43]}$ point to a perception that Western medicine is over-reliant on medication administration and that this is associated with drug side effects.

Furthermore, Chen et al. ${ }^{[13]}$ concluded from their analysis of complete datasets of TCM outpatient users, that diseases more generally associated with Western medicine are just as likely, as any other condition, to indicate the use of TCM in Taiwan. This latter study also challenges a linear historical explanation of the co-existence of TCM and Western medicine in pointing to a persistent increase in numbers using TCM in Taiwan over the last decade and a rate of use of TCM that peaks in the 30-40 years age group ${ }^{[13]}$. 
The significant pattern that emerged from the study was that of the use of TCM and Western medicine as therapeutic modalities that exist in quite separate domains. Each of them has specialized skills. TCM was not understood primarily as a therapy complementary to Western medicine. Yet, nor does the popular Western portrayal of Chinese medicine (in all its forms) as "alternative healing" reflect the ways in which TCM is situated in the lives of the study participants. Rather, the patterns of use of TCM as they emerged in the study reflect more so what Quah ${ }^{[8]}$ argues is "the weaving of health knowledge" accumulated by individuals "with the community's cosmology".

This understanding has implications for nurses given the current trend to mainstream integrative medicine modalities within Western medical systems. Indeed, several recent nursing studies are emphatic about the need for both more instruction on integrative medicine and the incorporation of evidence-based integrative medicine into health care curricula and the Western health care system ${ }^{[38,39,44]}$. Although there is movement for integrative medicine, the structure of TCM differs significantly from Western medicine and it may not be appropriate to apply the same standards in evaluating the two systems ${ }^{[45]}$.Taiwanese people with cancer may take for granted when using TCM $^{[48]}$; therefore nurses should have knowledge of and assess a patient's use of TCM and other integrative medicine therapies. In addition, more and more patients would like different options in health care, several research have indicated patients want to know more

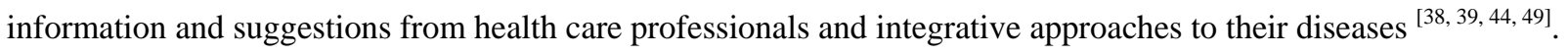

\section{Limitation}

The participants of this study were all recruited from Western medicine hospitals. To some degree, therefore, these participants were accepting of Western medical treatments, even though they were using some forms of TCM. The participants of this study did not include those who chose not to be treated in the Western medicine system.

\section{Conclusion}

Most people with cancer today typically undergo a complex and long term treatment journey following diagnosis. In circumstances where two distinct health cultures exist, people arguably encounter more complex decision making processes regarding their cancer treatments. In this study, the participants see 'different importance in Western medicine and TCM', 'taken for granted to use TCM', 'each has specialized skills in Western medicine and TCM' and 'different symptoms use different approaches (Western medicine or TCM)' in the process of using TCM. People with cancer insert themselves into co-existing health care systems and how, as active participants in a social world, people with cancer negotiate quite distinct therapeutic modalities of care.

In this study, participants used TCM based on interpretations of the present and against a background of an enduring cultural legacy grounded in ancient Chinese philosophical beliefs about health and healthcare. TCM use may affect quality of life over time and in relation to changing health states ${ }^{[46]}$, health care professionals should be aware patients' use of TCM and other integrative modalities. Recent attention given to the concepts of 'medical pluralism' and 'integrative medicine ${ }^{,[47]}$ to explain the evolution of health care in countries such as Taiwan do not necessarily illuminate the manifest differences in decision making on individual patient's use of TCM, integrative medicine and Western medicine. Further research is needed on decision making processes that lead to health care choices.

\section{Acknowledgments}

The authors would like to thank the anonymous cancer patients in Taiwan who were very generous and supportive to this study. Without their participation, this study could not be completed. The authors also extend thanks to the anonymous reviewers who gave so much of their valuable time and comments to this article. 


\section{Contributions}

Study design: SYW, CW and PY; data collection and data analysis: SYW, CW and PY and manuscript preparation: SYW, CW and PY.

\section{References}

[1] Wang SY, Yates P. Nurses' responses to people with cancer who use complementary and alternative medicine. International Journal of Nursing Practice. 2006; 12(5): 288-94. PMid:16942517 http://dx.doi.org/10.1111/j.1440-172X.2006.00584.x

[2] Wang SY, Yates P, Windsor C. (2006). Exploring the use of non Western medicine by people with cancer in Taiwan: A ground theory study. In 14th International Conference on Cancer Nursing: September 27th - 1st October 2006, The Sheraton Centre, Toronto, Canada.

[3] Thomson P, Jones J, Evans JMM, Leslie SJ. Factors influencing the use of complementary and alternative medicine and whether patients inform their primary care physician. Complementary Therapies in Medicine. 2012; 20(1-2): 45-53. PMid:22305248 http://dx.doi.org/10.1016/j.ctim.2011.10.001

[4] DeKeyser FG, Cohen BB, Wagner N. Knowledge levels and attitudes of staff nurses in Israel towards complementary and alternative medicine. Journal of Advanced Nursing. 2001; 36(1): 41-48. PMid:11555048 http://dx.doi.org/10.1046/j.1365-2648.2001.01941.x

[5] Engebretson J. Alternative and Complementary Healing: Implications for Nursing. Journal of Professional Nursing. 1999; 15(4): 214-23. http://dx.doi.org/10.1016/S8755-7223(99)80007-6

[6] Smith-Fassler ME, Lopez-Bushnell K. Acupuncture as complementary therapy for back pain. Holistic Nursing Practice. 2001; 15(3): 35-44.

[7] Chi C. Integrating Traditional Medicine into Modern Health Care System: Examining The Role of Chinese Medicine in Taiwan. Social Science and Medicine. 1994; 39(3): 307-321. http://dx.doi.org/10.1016/0277-9536(94)90127-9

[8] Quah SR. Traditional healing systems and the ethos of science. Social Science \& Medicine. 2003; 57(10): 1997-2012. http://dx.doi.org/10.1016/S0277-9536(03)00078-9

[9] Thomas RB, Bright MA. Global Health Issues. In: Bright MA, editor. Holistic Health and Healing. Philadelphia: F. A. Davis Company. 2002; 81-102.

[10] Farquhar J. Knowing Practice. The Clinical Encounter of Chinese Medicine. Boulder CO: Westview Press. 1994.

[11] Kaptchuk T. The Web That Has No Weaver. Chicago: Contemporary. 2000.

[12] Wang SY, Windsor C, Yates P. Introduction to grounded theory. The Journal of Nursing. 2012; 59(1): 91-95. (Original work published in Chinese)

[13] Chen FP, Chen TJ, Kung YY, Chen YC, Chou LF, Chen FJ, et al. Use frequency of traditional Chinese medicine in Taiwan. BMC Health Service Research. 2007; 7(26): 1-11. PMid:17199886

[14] Chiou CP. Ancillary use of complementary therapies by ESRD patients receiving hemodialysis in Taiwan. Journal of Nursing Research (Taiwan). 1999; 7(5): 398-406. (Original work published in Chinese)

[15] Duh YJ. The cultural influences in the medical behavior of the female breast cancer patients. VGH Nursing. 1992; 9(2): 127-133. (Original work published in Chinese)

[16] Wang TF. Residents' behaviors between traditional Chinese medicine and Western medicine in Taichung area. Public Health. 1990; 17: 21-33. (Original work published in Chinese)

[17] Chen YP, Tsang NM, Tseng CK, Lin XY, Hong JH. The use of alternative treatment in radiation cancer patients. Therapeutic Radiology Oncology.1999; 6: 295-300. (Original work published in Chinese)

[18] Chen FP, Chen TJ, Kung YY, Chen YC, Chou LF, Chen FJ, et al. Use frequency of traditional Chinese medicine in Taiwan. BMC Health Service Research. 2007; 7(26): 1-11. PMid:17199886

[19] Hu YH. The social space of alternative therapists: A field research. Thought and Speech. 1999; 36(2): 183-212. (Original work published in Chinese)

[20] Blumer H. Symbolic Interactionism: Perspective and Method. Englewood Cliffs: Prentice-Hall, Inc. 1969.

[21] Maines DR. The Faultline of Consciousness: A View of Interactionism in Sociology. New York: Aldine de Gruyter. 2001.

[22] Gusfield JR. A Journey with Symbolic Interaction. Symbolic interaction. 2003; 26(1): 119-39. http://dx.doi.org/10.1525/si.2003.26.1.119

[23] Strauss A, Corbin J. Basics of Qualitative Research: Grounded Theory Procedures and Techniques. Newbury Park: Sage; 1990.

[24] Stern PN. Grounded Theory Methodology: Its Uses and Processes. Image. 1980; XII(1): 20-3. 
[25] Strauss A, Corbin J. Basics of Qualitative Research: Techniques and Procedures for Developing Grounded Theory. Thousand Oaks: Sage. 1998.

[26] Eaves YD. A Synthesis Technique for Grounded Theory Data Analysis. Journal of Advanced Nursing. 2001; 35(5): 654-663. PMid:11529967 http://dx.doi.org/10.1046/j.1365-2648.2001.01897.x

[27] Holloway I, Wheeler S. Qualitative Research in Nursing. 2nd ed. Melbourne: Blackwell Publishing. 2002.

[28] Polit DF, Beck CT. Essentials of nursing research: Appraising evidence for nursing practice. Philadelphia: Lippincott Williams \& Wilkins. 2010.

[29] Lao L. Traditional Chinese Medicine. In: Jonas WB, Levin JS, editors. Essentials of Complementary and Alternative Medicine. Philadelphia: Lippincott Williams \& Wilkins. 1999; 216-232.

[30] Veith I. The Yellow Emperor's Classic of Internal Medicine. Los Angeles: University of California Press. 1972.

[31] Shih FJ. Concepts related to Chinese patients' perceptions of health, illness and person: issues of conceptual clarity. Accident and Emergency Nursing. 1996; 4(4): 208-15. http://dx.doi.org/10.1016/S0965-2302(96)90086-7

[32] Hsin LS, Chiu TY, Hu WY, Cheng SY, Chen CY. The behavior of alternative therapies among terminal cancer patients. Chinese Journal of Family Medicine. 1996; 6(3): 127-137. (Original work published in Chinese)

[33] Liu JM, Chu HC, Chin YH, Chen YM, Hsieh RK, Chiou TJ, et al. Cross Sectional Study of Use of Alternative Medicine in Chinese Cancer Patients. Japanese Journal of Clinical Oncology. 1997; 27(1): 37-41. PMid:9070339 http://dx.doi.org/10.1093/jjco/27.1.37

[34] Teng CH, Wang CS, Wu MH, Yang MJ. A community survey on the motivation and need for seeking "spirit calling" in Taiwan. Chinese Journal of Family Medicine. 1999; 9(4): 217-227. (Original work published in Chinese)

[35] Chi C, Lee JL, Lai JS, Chen SC, Chen CY, Chang SK. Utilization of Chinese Medicine in Taiwan. Alternative Therapies. 1997; 3(4): 40-53.

[36] Holroyd E. Health-Seeking Behaviors and Social Change: The Experience of the Hong Kong Chinese Elderly. Qualitative Health Research. 2002; 12(6): 731-750. PMid:12109720 http://dx.doi.org/10.1177/10432302012006002

[37] Martin KG. Medical Systems in A Taiwan Village: Ong-Ia-Kong, The Plague God as Modern Physician. In: Kleinman A, Kunstadter P, Alexander ER, Gale JL, editors. Medicine in Chinese Cultures: Comparative Studies of Health Care in Chinese and Other Societies. Washington, D.C.: U.S. Department of Health, Education, and Welfare Public Health Service. 1975; $115-141$.

[38] Wyatt G, Post-White J. Future Direction of Complementary and Alternative Medicine (CAM) Education and Research. Seminars in Oncology Nursing. 2005; 21(3): 215-24. PMid:16092810 http://dx.doi.org/10.1016/j.soncn.2005.04.011

[39] Zhang X. Integration of traditional and complementary medicine into national health care systems. Journal of Manipulative and Physiological Therapeutics. 2000; 23(2): 139-140. http://dx.doi.org/10.1016/S0161-4754(00)90085-X

[40] Andrews GJ. Placing the consumption of private complementary medicine: everyday geographies of older peoples' use. Health \& Place. 2003; 9(4): 337-349. http://dx.doi.org/10.1016/S1353-8292(02)00068-0

[41] Tovey P, Broom A. Oncologists' and specialist cancer nurses' approaches to complementary and alternative medicine and their impact on patient action. Social Science \& Medicine. 2007; 64 (12): 2550-2564. http://dx.doi.org/10.1016/j.socscimed.2007.02.010

[42] Vertheof M, Scott C, Hilsden R. A multi-method research study on the use of complementary therapies among patients with inflammatory bowel disease. Alternative Therapies in Health and Medicine. 1998;4:68-71.

[43] Wysong P. Many asthma patients using alternative medicine: conventional medicine seen as not treating the whole person. Medical Post. 1998; 34(35): 40.

[44] Rojas-Cooley MT, Grant M. Complementary and alternative medicine: Oncology nurses' experiences, educational interests, and resources. Oncology Nursing Forum. 2006; 33(3): 581-588. PMid:16676014 http://dx.doi.org/10.1188/06.ONF.581-588

[45] Chi C, Lee JL, Lai JS, Chen CY, Chang SK, et al. The practice of Chinese medicine in Taiwan. Social Science \& Medicine. 1996; 43(9): 1329-48. http://dx.doi.org/10.1016/0277-9536(95)00429-7

[46] Sewitch MJ, Rajput Y. A literature review of complementary and alternative medicine use by colorectal cancer patients. Complementary Therapies in Clinical Practice. 2010; 16(1): 52-56. PMid:20129411 http://dx.doi.org/10.1016/j.ctcp.2009.10.001

[47] Lew-Ting CY. Antibiomedicine belief and integrative health seeking in Taiwan. Social Science \& Medicine. 2005; 9: $2111-2116$. http://dx.doi.org/10.1016/j.socscimed.2004.08.068

[48] Wang, S. Y. Taiwanese people with cancer and non-Western medicine use (NWM) use: a ground theory study. 2007; Queensland University of Technology, Brisbane.

[49] Chang, F.-Y., \& Lu, C.-L. Treatment of Irritable Bowel Syndrome Using Complementary and Alternative Medicine. Journal of the Chinese Medical Association. 2009; 72(6): 294-300. http://dx.doi.org/10.1016/S1726-4901(09)70375-2 